\title{
CORRECTION
}

\section{Correction to: Complete genome sequences of two novel dicistroviruses detected in yellow crazy ants (Anoplolepis gracilipes)}

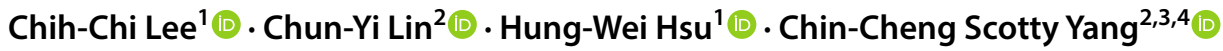

Published online: 2 September 2020

(c) Springer-Verlag GmbH Austria, part of Springer Nature 2020

\section{Correction to: Archives of Virology}

https://doi.org/10.1007/s00705-020-04769-2

Authors would like to correct the error in Fig. 1 which was incorrectly updated in the original publication.

The original article has been corrected.

Fig. 1 Genome structure of Anoplolepis gracilipes viruses 1 and 2 . Open reading frames are indicated by light gray rectangles, and conserved domains are indicated by dark gray rectangles
Anoplolepis gracilipes virus 1

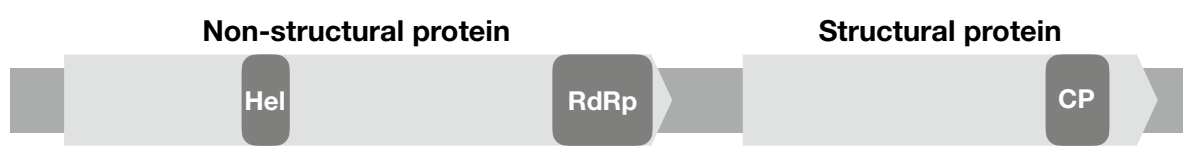

Anoplolepis gracilipes virus 2

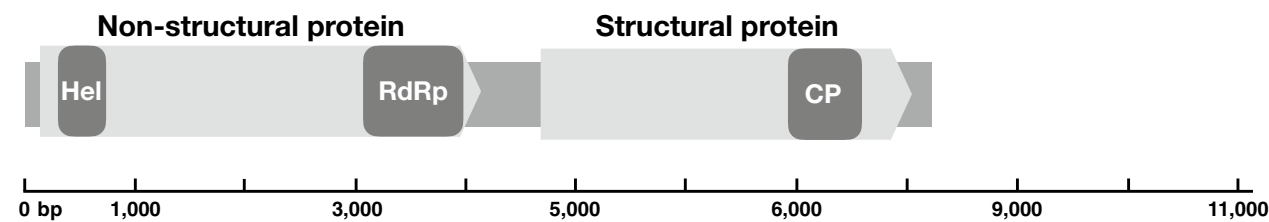

Publisher's Note Springer Nature remains neutral with regard to jurisdictional claims in published maps and institutional affiliations.

The original article can be found online at https://doi.org/10.1007/ s00705-020-04769-2.

Chin-Cheng Scotty Yang ccyang@rish.kyoto-u.ac.jp

1 Laboratory of Insect Ecology, Graduate School of Agriculture, Kyoto University, Kyoto 606-8502, Japan

2 Research Institute for Sustainable Humanosphere, Kyoto University, Kyoto 611-0011, Japan

3 Department of Entomology, Virginia Polytechnic Institute and State University, Blacksburg, VA 24061, USA

4 Department of Entomology, National Chung Hsing University, Taichung 402204, Taiwan 